\title{
POLÍMEROS PLÁSTICOS APLICADOS À CONSTRUÇÃO CIVIL: UM PROJETO DE ENSINO DE QUÍMICA VOLTẢDO À FORMAÇÃO PARA CIDADANIA
}

\author{
Fernando Elias Guckert \\ Instituto Federal de Santa Catarina - IFSC Campus São José (Brasil) \\ fefernandoelias@gmail.com · https://orcid.org/0000-0002-2118-3681 \\ Franciele Drews de Souza \\ Instituto Federal de Santa Catarina - IFSC Campus São José (Brasil) \\ francieledrews@gmail.com·.https://orcid.org/0000-0001-5144-8970
}

\begin{abstract}
Resumo. O presente trabalho consiste no relato de uma experiência de Ensino de Química, envolvendo o desenvolvimento do projeto de intervenção "Polímeros Plásticos aplicados à Construção Civil". O referido projeto fez parte das práticas de Estágio Supervisionado do Curso de Química - Licenciatura do Instituto Federal de Santa Catarina - campus São José, do qual o primeiro autor é acadêmico. Para além de descrever as atividades desenvolvidas, o objetivo deste artigo também é apresentar uma reflexão sobre em que medida o projeto pode ter propiciado um ensino voltado à formação para cidadania, conforme evidenciado por Santos e Schnetzler (1996). Ou seja, são feitas considerações sobre em que medida o projeto contemplou as seguintes características: [i] busca pela construção de conhecimentos que possibilitem a tomada de decisão crítica; [ii] abordagem de temas químicos sociais; [iii] uso de linguagem química simplificada e cálculos químicos sem tratamento algébrico excessivo; [iv] discussão do papel social da Ciência; [v] compreensão do papel investigativo da experimentação na construção de conhecimentos; [vi] articulação entre os níveis macroscópico e submicroscópico do conhecimento químico; [vii] extensão do conteúdo na medida de sua significação social; [viii] seleção de tópicos químicos fundamentais relacionados ao estudo das substâncias e dos materiais, suas propriedades, constituição e transformações químicas; e [ix] a adoção de estratégias metodológicas que proporcionem participação ativa dos estudantes (Santos e Schnetzler, 1996). A partir desta reflexão, evidencia-se que a maioria delas foi contemplada, podendo o projeto relatado ser compreendido como uma proposta de Ensino de Química para Cidadania.
\end{abstract}

Palavras-chave: Relato de Experiência, Ensino de Química, Formação para Cidadania.

\section{PLASTIC POLYMERS APPLIED TO CIVIL CONSTRUCTION: A PROJECT OF TEACHING OF CHEMISTRY FOCUSED ON THE TRAINING FOR CITIZENSHIP}

\begin{abstract}
This work is composed of the Report of an Experiment of Teaching Chemistry and contains the development of the intervention project "Plastic Polymers Applied to Civil Construction", which integrated the practices of Supervised Internship of Chemistry Degree course of the Instituto Federal de Santa Catarina - Campus São José, whose first author is academic. The other objective of this article, besides describing the activities developed, is to reflect on the extent to which the project may have provided a teaching focused on training for citizenship, as Santos and Schnetzler (1996) point out. In order to do so, we discuss the extent to which the project met the following attributes: [i] aim at generating knowledge that supports critical decision making; [ii] approach to social chemical issues; [iii] use of simplified chemical language and chemical calculations without excessive algebraic treatment; [iv] discussion of the social role of science; [v] understand the investigative role of experimentation in the generation of knowledge; [vi] articulation between the macroscopic and submicroscopic levels of chemical knowledge; vii] extension of content in proportion to its social significance; [viii] selection of the main chemical topics associated with the study of substances and materials, their properties, constitution and chemical transformations; and [ix]
\end{abstract}


the adoption of methodological strategies that enable active student participation (Santos and Schnetzler, 1996). Based on this reflection, it can be concluded that most of the requirements have been fulfilled, so that the reported project can be understood as a proposal of the Teaching of Chemistry for Citizenship.

Keywords: Experience Report, Teaching Chemistry, Training for Citizenship.

\title{
POLÍMEROS PLÁSTICOS APLICADOS A LA CONSTRUCCIÓN CIVIL: UN PROYECTO DE ENSEÑANZA DE LA QUÍMICA ORIENTADO A LA FORMACIÓN PARA LA CIUDADANÍA
}

\begin{abstract}
Resumen. Este trabajo consiste en el Relato de un Experimento de Enseñanza de la Química, que implica el desarrollo del proyecto de intervención "Polímeros plásticos aplicados a la construcción civil". Este proyecto formó parte de la pasantía supervisada de La Licenciatura en Química del Instituto Federal de Santa Catarina - Campus São José, del cual el primer autor es académico. El otro objetivo de este artículo, además de describir las actividades desarrolladas, es reflexionar sobre la medida en que el proyecto puede haber proporcionado una educación centrada en la formación para la ciudadanía, como lo señalan Santos y Schnetzler (1996). Para hacerlo, discutimos en qué medida el proyecto cumplió con los siguientes atributos: [i] apunta a generar conocimiento que apoye la toma de decisiones críticas; [ii] enfoque a temas de química social; [iii] uso de lenguaje químico simplificado y cálculos químicos sin tratamiento algebraico excesivo; [iv] discusión del papel social de la ciencia; [v] entender el papel investigativo de la experimentación en la generación de conocimiento; [vi] articulación entre los niveles macroscópicos y submicroscópicos del conocimiento químico; vii] extensión del contenido en la medida de su significado social; [viii] selección de los principales temas químicos asociados con el estudio de sustancias y materiales, sus propiedades, constitución y transformaciones químicas; y [ix] la adopción de estrategias metodológicas que permitan la participación activa de los estudiantes (Santos i Schnetzler, 1996). La reflexión proporciona indicios de que la mayoría de los requisitos se han cumplido, por lo que el proyecto informado puede entenderse como una propuesta de la Enseñanza de La Química para la Ciudadanía.
\end{abstract}

Palabras clave: Relato de Experiencia, Enseñanza de La Química, Formación para la Ciudadanía.

\section{Introdução}

A partir do crescente desenvolvimento de pesquisas em Ensino de Química, em especial desde meados de 1980, muitas críticas têm sido feitas ao que tradicionalmente é ensinado e desenvolvido nas aulas de Química das escolas de Educação Básica do Brasil (Schnetzler, Aragão, 1995; Santos, Schnetzler, 1996; Chassot, 1996; Schnetzler, 2002). Dentre as principais, destacam-se aquelas referentes à ênfase na memorização de informações, de nomes e de fórmulas, bem como à abordagem de conhecimentos fragmentados e não-relacionados à realidade e/ou ao cotidiano dos alunos, implicando dificuldades de aprendizagem e no que Chassot (1996) denominou de um ensino (in)útil. Útil para manter o "estado das coisas", e inútil para o desenvolvimento de uma compreensão mais crítica do mundo e da própria ciência Química, no que se refere às implicações ambientais, sociais, políticas e econômicas de suas aplicações tecnológicas. Assim, de acordo com a comunidade brasileira de Educação Química, em geral, é imprescindível que o Ensino de Química seja reformulado para que possa atender à função social estabelecida para toda Educação Básica do país: a formação para o exercício crítico da Cidadania (Santos e Schnetzler, 1996; Chassot, 1996; Schnetzler, 2002). 
Tendo esses apontamentos em vista, dentre as práticas propostas para os Estágios Supervisionados do curso de Química - Licenciatura do Instituto Federal de Santa Catarina - campus São José (IFSC-SJ), destaca-se a elaboração e o desenvolvimento de projetos de intervenção, que buscam superar os aspectos acima sinalizados. Como? Organizando o ensino a partir da contextualização dos conteúdos de Química, preferencialmente, por meio da abordagem temática; da assunção de diferentes estratégias metodológicas e recursos didáticos; da problematização dos conhecimentos prévios dos estudantes; da participação ativa destes sujeitos no processo de ensino e aprendizagem; e da utilização de organizadores conceituais dos chamados Projetos Criativos Ecoformadores (PECs) com base em Torre e Zwierewicz, 2009.

Neste trabalho, busca-se relatar a proposta de ensino de Química de um destes projetos. Qual seja, o projeto intitulado "Polímeros Plásticos aplicados à Construção Civil", que foi elaborado e desenvolvido pelo primeiro autor, sob a orientação das demais autoras, em uma turma do $3^{\circ}$ ano (noturno) do Ensino Médio da Escola de Educação Básica Irmã Maria Teresa (EEBIMT), localizada no município de Palhoça - SC (BR). Assim, discorre-se brevemente sobre o processo de elaboração do projeto, enfatizandose como e por que se deu a escolha da referida temática para contextualização dos conteúdos de Química, a partir das atividades do estágio de observação. Também, apresentam-se quais foram os objetivos do projeto, os conteúdos trabalhados e as atividades desenvolvidas aula por aula, durante o estágio de regência.

Contudo, para além de descrever a referida experiência, neste relato, também apresenta-se uma reflexão sobre em que medida a proposta do projeto de intervenção "Polímeros Plásticos aplicados à Construção Civil" pode ter propiciado um Ensino de Química na perspectiva da formação para Cidadania, conforme defendido, nas últimas décadas, pela comunidade de Educação Química e caracterizado por Santos e Schnetzler (1996). Com isso, espera-se contribuir com as discussões e com a elaboração de outras propostas voltadas à transformação da (in)utilidade do Ensino de Química, como preconizado por Chassot (1996).

\section{Ensino de Química para Cidadania}

Conforme mencionado anteriormente, especialmente nas últimas três décadas, educadores químicos brasileiros têm apontado a necessidade de reformulação de currículos, metodologias e práticas pedagógicas na área de ensino em questão. No caso da Educação Básica, as mudanças propostas têm sido justificadas, dentre outros aspectos, pelas influências da Química na sociedade, as quais passaram a exigir dos cidadãos um mínimo de conhecimento químico para poder participar de forma crítica da sociedade tecnológica atual, especialmente, na tomada de determinadas decisões. Desta forma, para a referida comunidade científica, o ensino de Química tradicionalmente desenvolvido nas escolas deve ser reformulado de modo a buscar a construção de conhecimentos para o exercício crítico da cidadania - uma função social, inclusive, estabelecida para toda Educação Básica do país em legislação pertinente (Santos e Schnetzler, 1996, Schnetzler, 2002).

O que isso significa? Em trabalho publicado em 1996, Santos e Schnetzler apresentaram resultados de uma investigação exatamente com o objetivo de responder a esta pergunta. E, portanto, identificar quais seriam as principais características de um ensino de Química voltado à formação para a cidadania. Para tanto, realizaram entrevistas 
com doze educadores químicos considerados referências nacionais devido à atuação na área de Educação Química e à experiência no magistério de nível superior e médio e em cursos de formação de professores.

Nesta pesquisa, Santos e Schnetzler (1996) identificaram que, de acordo com a maioria dos entrevistados, o principal objetivo do ensino de Química para cidadania é a construção de conhecimentos que possibilitem a tomada de decisão crítica. Ou seja, que possibilitem o desenvolvimento da "... capacidade de tomar decisões fundamentadas em informações e ponderadas as diversas consequências decorrentes de tal posicionamento" (Santos e Schnetzler, 1996, p. 29). Nesse sentido, evidenciaram também a necessidade de abordagem de conceitos químicos que forneçam ferramentas para interpretação e apropriação da linguagem científica, buscando a compreensão e a possível transformação do contexto social do qual os alunos fazem parte.

Para alcance deste objetivo, os educadores químicos também sinalizaram características referentes aos conteúdos a serem ensinados, às atividades de ensinoaprendizagem a serem desenvolvidas, bem como aos procedimentos de avaliação a serem adotados em sala de aula. A seguir, apresenta-se, na Tabela 1, uma síntese de aspectos gerais que devem compor o conteúdo programático do ensino de Química para formar o cidadão, considerando-se a categorização realizada por Santos e Schnetzler (1996) a partir dos dados das entrevistas.

\section{Tabela 1}

Síntese das características gerais do conteúdo programático do Ensino de Química voltado para Cidadania, de acordo com o trabalho de Santos e Schnetzler (1996)

\begin{tabular}{|c|c|}
\hline Característica & Descrição \\
\hline $\begin{array}{l}\text { Abordagem de temas } \\
\text { químicos sociais }\end{array}$ & $\begin{array}{l}\text { Temas destinados à contextualização do ensino, envolvendo a articulação } \\
\text { entre conteúdos de Química e o cotidiano dos alunos, o qual não deve ser } \\
\text { apresentado como curiosidade apenas. }\end{array}$ \\
\hline $\begin{array}{l}\text { Linguagem química } \\
\text { simplificada e cálculos } \\
\text { químicos sem tratamento } \\
\text { algébrico excessivo }\end{array}$ & $\begin{array}{l}\text { Parte importante do Ensino de Química envolve a apreensão da linguagem } \\
\text { científica, que não deve ser abordada de forma exagerada ou apenas para } \\
\text { memorização; mas deve ser explorada de forma a fazer com que os alunos } \\
\text { compreendam sua importância para a Química, sua simbologia e seus } \\
\text { princípios gerais, em especial, quando frequentemente utilizada em } \\
\text { meios de comunicação, por exemplo. }\end{array}$ \\
\hline $\begin{array}{c}\text { Discussão do papel social da } \\
\text { ciência }\end{array}$ & $\begin{array}{l}\text { É necessário que os alunos compreendam a Ciência como atividade } \\
\text { humana em construção, o que pode feito por meio de estudos de aspectos } \\
\text { históricos do conhecimento químico. }\end{array}$ \\
\hline $\begin{array}{l}\text { Experimentação como } \\
\text { método investigativo da } \\
\text { ciência Química }\end{array}$ & $\begin{array}{l}\text { Não apresenta necessidade de laboratórios sofisticados para realização de } \\
\text { experimentos, pois estes devem ser realizados de modo a possibilitar a } \\
\text { compreensão de fenômenos químicos e do papel investigativo da } \\
\text { experimentação na construção de conhecimentos químicos, e não para } \\
\text { comprovar conceitos abordados em sala de aula. }\end{array}$ \\
\hline $\begin{array}{l}\text { Articulação entre os níveis } \\
\text { macroscópico e } \\
\text { submicroscópico do } \\
\text { conhecimento químico }\end{array}$ & $\begin{array}{l}\text { O conteúdo deve ser abordado tanto no nível macroscópico } \\
\text { (fenomenológico) como no submicroscópico (teórico-conceitual; } \\
\text { atômico-molecular), sendo que esta última abordagem deve ser } \\
\text { simplificada ou utilizar modelos simples, tendo em vista sua } \\
\text { complexidade e abstração. No nível macroscópico, devem ser valorizadas } \\
\text { as propriedades dos materiais e suas transformações. }\end{array}$ \\
\hline $\begin{array}{l}\text { Extensão do conteúdo na } \\
\text { medida de sua significação } \\
\text { social }\end{array}$ & $\begin{array}{l}\text { O conteúdo deve ser selecionado de forma a ter significação social para os } \\
\text { alunos. É mais importante os alunos compreenderem os conceitos } \\
\text { químicos que são básicos para a Cidadania, do que ter um estudo amplo } \\
\text { de vários conceitos sem sua devida compreensão e com um fim em si } \\
\text { mesmos. }\end{array}$ \\
\hline
\end{tabular}




$\begin{array}{cl}\begin{array}{c}\text { Extensão do conteúdo na } \\ \text { medida de sua significação } \\ \text { social }\end{array} & \begin{array}{l}\text { O conteúdo deve ser selecionado de forma a ter significação social para os } \\ \text { alunos. É mais importante os alunos compreenderem os conceitos } \\ \text { químicos que são básicos para a Cidadania, do que ter um estudo amplo } \\ \text { de vários conceitos sem sua devida compreensão e com um fim em si } \\ \text { mesmos. }\end{array} \\ \begin{array}{c}\text { Nem todos os tópicos comumente abordados em livros didáticos devem } \\ \text { fundamentais }\end{array} & \begin{array}{l}\text { ser abordados ou com grande aprofundamento. Os conceitos a serem } \\ \text { ensinados e aprendidos devem girar em torno estudo das substâncias e dos } \\ \text { materiais, de suas propriedades, constituição e transformações químicas, } \\ \text { compreendendo assim aspectos gerais dos objeto de estudo da Química. }\end{array}\end{array}$

Desse modo, o ensino de conceitos científicos, em geral, e da área da Química, em particular, seria utilizado para desenvolver habilidades básicas para que os sujeitos possam participar da sociedade atual e fazer julgamentos, ponderando as consequências da sua tomada de decisão.

No que se refere às atividades de ensino-aprendizagem, Santos e Schnetzler (1996) identificaram que, em se tratando de um ensino de Química na perspectiva da formação para a cidadania, devem ser privilegiadas aquelas que proporcionam a participação ativa dos estudantes e que destacam seu papel no processo de construção do conhecimento. Neste sentido, dentre as atividades e/ou princípios metodológicos sugeridos pelos participantes da pesquisa estão: debates em sala de aula; realização de simulações; leitura, análise e discussão de textos; solução de problemas; visitas a indústrias; método investigativo; método de projetos; projeção de filmes e vídeos, dentre outros. 33):

Tendo em vista todas estas características, segundo Santos e Schnetzler (1996, p.

A tese geral apresentada pelos educadores é a de que o ensino de química atual não tem atendido às necessidades de um curso voltado à formação da cidadania ... Isso implica reformulação e adoção de várias medidas que venham a mudar tal situação. Implica, ainda, desenvolvimento de estudos sobre propostas curriculares que abranjam desde a adoção de conteúdos mais relevantes até sugestões de estratégias de ensino e de avaliação que se adaptem aos objetivos relacionados com a cidadania.

Dentre as medidas que têm sido adotadas nas últimas décadas, mencione-se a inserção destas discussões e estudos em cursos de formação inicial de professores de Química do Brasil, como é o caso da Química - Licenciatura ofertada pelo Instituto Federal de Santa Catarina - campus São José (IFSC-SJ). Neste curso, no qual o primeiro autor do presente artigo é acadêmico e as demais, docentes, um dos componentes curriculares que trata da necessidade de reformulação do ensino de Química é o denominado Fundamentos para o Ensino de Química (FEQ), cujos alguns de seus objetivos são:

Refletir sobre a (in)utilidade do ensino de Química tradicionalmente estabelecido e disseminado nas escolas brasileiras de nível médio, tendo em vista a problematização e a caracterização realizada por pesquisadores da área de Educação Química ... Refletir sobre a função social do ensino de Química de nível médio na atualidade e os desafios para sua concretização. Analisar propostas elaboradas e desenvolvidas pela comunidade de professores químicos brasileiros para melhoria dos processos de ensino-aprendizagem 
de conhecimentos químicos na Educação Básica, identificando e discutindo seus fundamentos e pressupostos (IFSC, 2014, p. 61).

Foi, inclusive, a partir das discussões e atividades realizadas em FEQ que o primeiro autor deste artigo tomou conhecimento da perspectiva de ensino de Química para cidadania. E em vista disso, estudou o trabalho de alguns autores sobre o assunto, como o de Wildson Luiz P. Santos e Roseli P. Schnetzler, adotado aqui como referencial teórico.

Além do componente curricular de FEQ, outros igualmente buscam fornecer subsídios para formação de professores preocupados com enfoque na cidadania, sendo esses Didática da Química (DIQ) e Metodologias para o Ensino de Química (MEQ). Ao assim propor, o curso de Química - Licenciatura do IFSC-SJ, espera contribuir com a formação de futuros docentes de Química capazes de desenvolver práticas pedagógicas que superem a (in)utilidade do Ensino de Química (Chassot, 1996) e possibilitem a formação de alunos críticos, agentes de transformação do meio social do qual fazem parte.

Destaca-se, contudo, que esse intuito não apenas se faz presente na proposta pedagógica dos componentes curriculares de FEQ, DIQ e MEQ, mas também em outros, como é o caso dos Estágios Supervisionados do curso em questão, conforme se busca evidenciar na próxima seção. Assim, discutem-se os principais pressupostos teóricometodológicos dos projetos de intervenção elaborados e desenvolvidos nos estágios, dando-se ênfase à perspectiva dos Projetos Criativos Ecoformadores (PCEs). Com isso, porém, não se pretende inferir qualquer tipo de relação teórica entre os PCEs e a perspectiva do Ensino de Química para formação da Cidadania. O objetivo é tão somente apresentar em que medida a metodologia em questão foi tomada como referência na elaboração e desenvolvimento do projeto de intervenção "Polímeros Plásticos aplicados à construção civil", relatado e discutido neste trabalho.

\section{Projeto de Intervenção com base em Projetos Criativos Ecoformadores (PCEs): uma proposta dos estágios em Química do IFSC-SJ}

Os Projetos Criativos Ecoformadores (PCEs), assim como descreve Pukall (2017), devem utilizar situações reais do cotidiano dos alunos, possibilitando articulação de conhecimentos acadêmicos com o cotidiano dos discentes, estimulando a construção de conhecimentos e a transformação da realidade.

A metodologia dos PCEs é recente. Segundo Pukall (2017, p. 63), ela “... foi criada em 2009, por Marlene Zwierewicz e Saturnino de la Torre após muitos encontros e discussões em busca de um referencial metodológico criativo e com base em um ensino a partir da vida e para a vida ...".

Um dos principais aspectos relacionados a esta metodologia, elaborada por Torre e Zwierewicz (2009), é a tomada de consciência da realidade vivida, para propiciar aosalunos a conscientização sobre a importância do desenvolvimento sustentável.

Tomar consciência sobre a nossa realidade é muito importante no PCE, pois assim fica claro o que temos e o que queremos ... A partir do momento que tomamos consciência passamos a analisar a realidade e sentimos a necessidade de legitimar nossas ações. Com isso, promovemos um desenvolvimento sustentável nos estudantes, onde há a preocupação com o eu, com o outro e com o meio. (Pukall, 2017, p.64). 
Tendo como um de seus pressupostos teóricos a Ecoformação, a proposta dos PCEs apresenta preocupação com a formação e o desenvolvimento integral do ser humano, considerando tanto aspectos socioculturais como ecológicos do meio em que vive. Indo além da preocupação com a conservação da natureza, ela propõe que seja abrangida também, no processo de construção de conhecimentos, a preocupação com as pessoas, valorizando-as como cidadãs da Terra. Neste sentido, como descrito por Pukall, Souza e Silva e Silva (2017), a metodologia dos PCEs propõem mudanças e reflexões no modo de ser e agir dos sujeitos participantes, possibilitando a formação de cidadãos(ãs) críticos e preocupados com os demais sujeitos e com o meio em que vivem.

Outro aspecto a ser destacado é a busca pela autonomia dos alunos, almejando a formação de sujeitos protagonistas de seu próprio processo de construção de conhecimento. Para Pukall, Souza e Silva e Silva (2017), a escola é um espaço formativo propício em que os docentes deveriam utilizar práticas de ensino que estimulassem este aspecto, a criatividade, o espírito de participação coletiva nos alunos.

Partindo destes e de outros pressupostos, para a realização de um PCE, Torre e Zwierewicz (2009) propuseram diferentes etapas, as quais denominaram de organizadores conceituais. São eles: o epítome, a legitimação teórica e pragmática, as perguntas geradoras, as metas, os eixos norteadores, os itinerários, as coordenadas temporais, a avaliação emergente e a polinização. Para os propósitos deste artigo, dois destes organizadores conceituais chamam a atenção: a problematização inicial, chamada de epítome, cuja função é ressaltar a problemática de ensino e cativar a participação dos alunos no processo de realização dos projetos; e o "fechamento" das atividades relacionadas ao longo do desenvolvimento do PCE, denominada de polinização, momento em que os resultados são socializados com a comunidade escolar e/ou para além dela.

Considerando as potencialidades da metodologia dos PCEs, desde 2015 tem se buscado utilizá-la no contexto dos estágios supervisionados do curso de Química Licenciatura do IFSC-SJ, a partir da proposta organizacional e pedagógica definida para esses estágios no Projeto Pedagógico do Curso (PPC). Partindo da pesquisa como princípio educativo nas práticas de estágio, este documento, prevê, dentre outros aspectos, a elaboração de projetos de intervenção no Estágio Supervisionado II e o seu desenvolvimento nas escolas-campo durante o Estágio Supervisionado III (IFSC, 2014). Acerca destes, explicam Aguiar, Viella e Pereira (2017, p. 135) que:

Os projetos de intervenção adotados nas práticas de estágio pretendem organizar o ensino pela contextualização via abordagem temática, buscando articular o tema discutido em sala com a realidade dos estudantes das escolas onde o estágio é desenvolvido. Para alcançar tal objetivo, são utilizadas diferentes estratégias metodológicas e recursos didáticos, além da realização de investigações e problematizações sobre os conhecimentos prévios dos alunos. A participação ativa dos alunos dos campos de estágio na construção dos projetos e no processo de ensino e aprendizagem desenvolvido nas escolas caracteriza-se como uma possibilidade de cativá-los, além de buscar que a aprendizagem ocorra, potencializar a articulação entre conteúdos curriculares e as demandas da realidade em que os estudantes se inserem.

Embora os referidos projetos não sigam exatamente a estrutura organizacional e de desenvolvimento de um PCE, conforme proposto por Torre e Zwierewicz (2009), alguns organizadores conceituais têm sido levados em consideração, como salientado ainda por Aguiar, Viella e Pereira (2017, p. 135-136): 
Tendo como suporte a metodologia dos Projetos Criativos Ecoformadores (PCE), os projetos de intervenção construídos pelos licenciandos ... possuem o epítome como primeira etapa de seu desenvolvimento, que busca o "encantamento" dos estudantes ... para o tema que será discutido, e a etapa final é a polinização, que visa socializar e difundir os resultados alcançados pelos estudantes ... do campo de estágio. Além dessas etapas, os projetos contam ainda com legitimação teórica e pragmática, perguntas geradoras, objetivo geral e uma sequência didática, que é o itinerário de desenvolvimento do projeto. O itinerário é composto pelo conjunto de atividades, pelos objetivos de aprendizagem, pelas estratégias, intervenções e avaliações planejadas aula por aula para o desenvolvimento da temática proposta para a contextualização do ensino de Ciências/Química.

Tendo-se estes aspectos em vista, a construção do projeto de intervenção "Polímeros Plásticos aplicados à Construção Civil" deu-se a partir da proposta do Estágio Supervisionado II, onde foram realizadas práticas de observação participante, registros em diários de campo, análise do Projeto Político-Pedagógico da E.E.B. Irmã Maria Teresa e a aplicação de um questionário para coleta de informações sobre os sujeitos que participariam do projeto. Dentre as informações levantadas, destaca-se aquelas referentes à pertinência e relevância da temática para contextualização do ensino de Química, das atividades a serem desenvolvidas e das formas de avaliação; e sobre os alunos, buscando integração entre formação social, conteúdo científico e preocupação ambiental. Essas informações foram utilizadas para a construção da Legitimação Pragmática do projeto, sendo a escolhida "Polímeros Plásticos utilizados em Construções Civis" a mais pontuada para temática do projeto. Desta forma, a proposta foi construída com base nas escolhas dos alunos, tornando mais relevante a execução e participação pelos mesmos.

Outro fator relevante de ser mencionado é que a Sequência Didática foi replanejada, em alguns momentos durante a execução do projeto, no componente curricular Estágio Supervisionado III, para melhor adequação ao tempo de execução das atividades e adequação ao ritmo dos alunos. A seguir, descreve-se as ações realizadas em cada uma das aulas de regências.

\section{Projeto de Intervenção: Polímeros Plásticos aplicados à Construção Civil}

Na sequência serão relatos o processo de construção e execução do Projeto de Intervenção "Polímeros Plásticos aplicados à Construção Civil", com participação dos alunos.

\section{Sobre a escolha e a relevância da temática do projeto:}

Com relação à escolha da temática, os alunos tiveram participação nesse processo, em um contexto em que alguns descreveram que seria interessante o estudo desse tema por terem pouco conhecimento na área e preocupação com o meio ambiente. Alguns alunos justificaram que não gostaram da temática sugerida pelo fato de não gostarem de estudar Química. Este "não gostar" foi relacionado ao número excessivo de conteúdos e memorizações abordadas em aula, desvinculadas do contexto social dos alunos, evidenciando a mudança que deveria ser realizada nos processo de ensino e aprendizagem em Química. 
A seguir, será apresentado um trecho da Legitimação Pragmática do projeto de intervenção, com justificativa do autor quanto à escolha temática em questão para contextualização do ensino:

... a temática "Polímeros Plásticos aplicados à Construção Civil" me pareceu ser muito interessante. Essa possibilita abordar conceitos sobre sustentabilidade, no que diz respeito à utilização de materiais de melhor eficiência para substituição de metais, concretos, madeira, etc e reciclagem; também questões ambientais sobre extração da matéria-prima para produção de polímeros plásticos e impactos no meio natural; além de questões econômicas e sociais, no que compete questões de custo-benefício. Vejo também como uma oportunidade para abordagem de conteúdos científicos em sala de aula. Através da estrutura dos polímeros plásticos, pode-se descrever polaridade de moléculas, forças intermoleculares e até isomeria (onde fazer um recorte da molécula, e trabalhar os conceitos desejados), conteúdos previstos para serem trabalhados no $3^{\circ}$ bimestre de aula para os $3^{\circ} \mathrm{s}$ anos da EEBIMT.

A partir da abordagem deste tema, objetivou-se a compreensão de impactos socioeconômicos e ambientais da utilização de produtos cerâmicos, metálicos, poliméricos (plásticos), entre outros, pela construção civil. E, também conhecer como é feita a extração de matéria-prima, produção, reciclagem e descarte desses produtos.

Neste projeto, foi dado ênfase ao debate e troca de ideias, almejando tentativas de conscientização envolvendo a problemática (de Polímeros Plásticos) e impactos no meio natural através da má-utilização desses produtos acima citados, além do descarte incorreto e reciclagem, para incentivo de preservação do meio ambiente e formação de pensamento crítico para vida em sociedade dos alunos.

Deste modo, o projeto desenvolvido buscou desenvolver nos alunos a preocupação com o meio ambiente e o meio social em que estão inseridos, articulando o conteúdo programático e questões socioambientais, visando a desenvolver pensamento crítico nos sujeitos participantes da execução dos projetos. Quase na totalidade das aulas foram abordados tópicos de educação ambiental de forma transversal, buscando a formação crítica dos alunos.

Para o estudo da temática a partir de conhecimentos da área da Química, foram selecionados os seguintes conteúdos programáticos previstos para o $3^{\circ}$ ano do Ensino Médio da E.E.B. Irmã Maria Teresa, os quais foram debatidos de forma processual, respeitando pré-requisitos para construção de conhecimentos:

- $\quad$ conceito de Polímeros, estrutura e classificação em naturais e sintéticos;

- $\quad$ identificação e classificação de polímeros sintéticos de acordo com comportamento mecânico (com ênfase em plásticos);

- processos de síntese de polímeros (abordando impactos gerados pela síntese e descarte incorreto de polímeros sintéticos);

- tópicos de funções orgânica (identificação e nomenclatura das funções ácido carboxílico, álcool e amina);

- $\quad$ conceitos envolvendo densidade (para seleção e reciclagem de plástico);

- $\quad$ polaridade de moléculas;

- forças intermoleculares aplicadas em polímeros. 


\section{Sequência Didática}

Para melhor descrever as atividades do projeto, e depois estabelecer considerações a respeito da formação para cidadania de cada aula, apresenta-se a seguir a Sequência Didática desenvolvida, desmembrada em oito aulas, com duração de 80 minutos cada.

\section{Aula 01}

Na primeira aula foi realizada uma atividade investigativa, na qual se solicitou aos alunos que tirassem fotos de materiais plásticos existentes na estrutura predial da escola. O objetivo era fazer com que eles percebessem estes materiais presentes na construção do espaço escolar e também em seu dia a dia, bem como a quantidade com que são utilizados. Após tirarem as fotos, foi proposta a socialização das mesmas, por meio de sua projeção, a partir da qual os estudantes foram instigados a explicar o porquê da escolha daqueles materiais fotografados. Com isso, buscou-se compreender $\mathrm{e}$ problematizar os conhecimentos prévios dos estudantes acerca do que são os materiais plásticos e quais suas características. Somente após esta discussão preliminar, conceitos científicos foram abordados, no que se refere à definição química dos plásticos, como materiais poliméricos, estabelecendo relações com as informações previamente apresentadas pelos alunos.
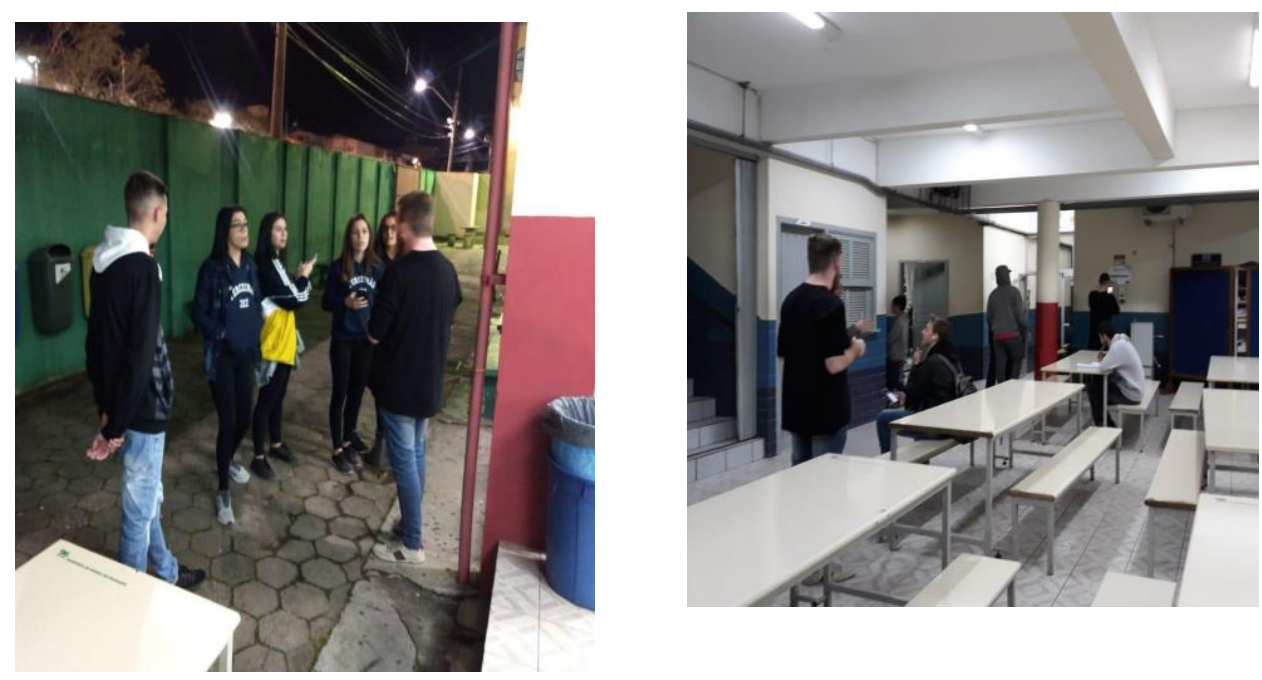

Figuras 2 e 3. Atividade de percepção de polímeros em prédio escolar. Fonte: acervo dos autores (2019).

Aula 02

No que se refere aos conceitos científicos, nessa aula, foram apresentados e discutidos aqueles referentes à classificação dos polímeros em naturais e sintéticos, bem como às possíveis formas de classificação destes últimos a partir de seu comportamento mecânico, com ênfase aos polímeros plásticos. Nesta exposição dialogada do conteúdo, foi novamente realizado o levantamento dos conhecimentos prévios dos alunos, com vistas à sua valorização e problematização. Para exemplificação e melhor compreensão 
dos conceitos abordados, nesta aula também foram apresentados aos estudantes exemplos de materiais plásticos existentes no cotidiano, dentre eles alguns dos mais utilizados na construção civil, enfatizando-se a diferença de suas características e constituição.

Na sequência da aula, foi utilizada uma apresentação de slides, com informações de efeitos dos materiais convencionais para o meio ambiente, com o objetivo de incentivo e fornecer conhecimentos para os alunos para a atividade de debate que foi planejada na sequência; os alunos puderam expor suas opiniões sobre a temática de impactos gerados pela construção civil, sendo instigados a apontar alternativas para solução das problemáticas geradas pelos alunos. Também foram abordados conceitos de exploração de matéria-prima, utilização, reutilização e descarte. Neste debate, os alunos foram estimulados a expressar suas opiniões, construindo conhecimentos coletivamente e um posicionamento crítico perantes situações de problemas sociais.

Aula 03

Nessa aula, foram apresentados conceitos relacionados à síntese de polímeros, contexto no qual as informações foram apresentadas em uma dinâmica, em que as mãos dos alunos foram utilizados como monômeros, de modo que foi exemplificado o processo de polimerização pelo licenciando. Também foram adentrados em conceitos de matériaprima e como são extraídas, com ênfase à produção de Cloro e Etileno, principais materiais para síntese de PVC, sendo apontado como um dos plásticos mais utilizados na construção civil. Na sequência, foram discutidas alternativas para reutilização de plásticos e reciclagem, além de informações contidas em um material com fotos, instigando os alunos a refletirem sobre a utilização e impactos do petróleo, quando usado de forma inconsciente.

Na sequência, foi proposto um debate, no qual as informações trabalhadas foram a de utilização de matéria-prima para síntese de plásticos, sendo a principal fonte o petróleo, envolvendo seus impactos para a natureza e sociedade.

Por fim, foi proposta uma atividade de produção textual, que possibilitou a pesquisa de informações, além de almejar a expressão de opiniões dos alunos e solicitar informações sobre matéria-prima, síntese, reutilização e reciclagem de plásticos.

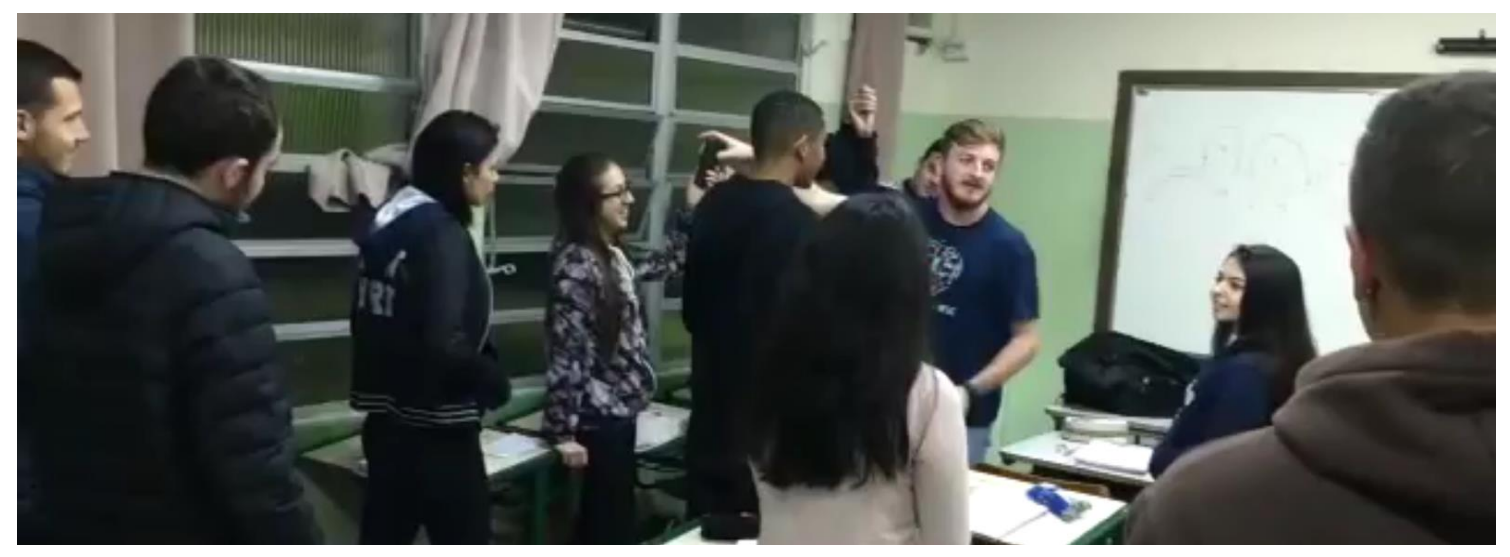

Figura 4. Dinâmica realizada para exemplificação do processo de polimerização de polímeros.

Fonte: acervo dos autores (2019). 
Aula 04 e Aula 05

Nas presentes aulas, foram abordadas informações sobre as funções orgânicas Álcool, Ácido Carboxílico e Amina, com perfil tradicional de abordagem. Definição, características e nomenclatura das funções foram apresentados de forma oral e escrita no quadro, além de exercícios para prática por parte dos alunos. Um resumo para auxiliar os alunos também foi entregue, para ajudar no processo de resolução dos exercícios propostos.

Os exercícios foram solicitados como forma de avaliação dos alunos, contexto em que desenvolveram a atividade em casa e o estagiário-docente corrigiu também a atividade em sala de aula.

Especificamente na Aula 05, foi apresentada a proposta do trabalho de polinização, etapa em que os alunos, em grupos, deveriam buscar informações específicas sobre um material plástico utilizado na construção civil. As informações que deveriam ser pesquisadas são: monômero de constituição, massa molar média, densidade, classificações físicas e químicas do material, além da aplicação na construção civil, processos de extração de matéria-prima e síntese do material. Cada grupo deveria escolher um dos seguintes materiais: PVC (Policloreto de Vinila), CPVC (Policloreto de Vinila Clorado), PE (Polietileno), PS (Poliestireno), PP (Polipropileno), PPO (Polioxifenileno), PMMA (Polimetacrilato de Metila), PC (Policarbonato), PVA (Poliacetato de Vinila) e PET (Politereftalato de Etileno). As informações almejadas envolvem matéria-prima, processo de síntese, estrutura, utilização, reutilização e reciclagem desse material. Além do material a ser pesquisado, foi solicitada uma apresentação para socialização com os colegas.

\section{Aula 06}

A presente aula foi destinada para que os alunos realizassem a pesquisa do trabalho de polinização, além de tirarem dúvidas para o melhor encaminhamento das atividades. Ao fim da aula, foi solicitado que os alunos completassem algumas informações sobre o material específico de pesquisa no quadro, para socialização prévia de informações com os colegas. Ainda possibilitando articulação com os conceitos científicos abordados, solicitou-se também que cada grupo elaborasse um nome criativo com base em seu material de pesquisa.

\section{Aula 07}

Nessa aula, muitos conceitos científicos foram abordados, sendo estes: definição de polímeros, classificação e suas propriedades mecânicas, interações intermoleculares em polímeros e densidade. Os conceitos foram abordados de forma a situar ascaracterísticas mecânicas apresentadas pelos diferentes tipos de polímeros, justificando as diferentes aplicações desses materiais na construção civil. Também foi discutida a relação entre a densidade de alguns materiais poliméricos apresentados durante a execução do projeto e os conceitos de interações intermoleculares e reciclagem desses materiais.

Após a abordagem teórica citada acima, foi realizado, de forma demonstrativa, um experimento que diferenciava alguns polímeros plásticos a partir de suas densidades. As diferenças de densidade foram investigadas a partir da observação do comportamento dos materiais em três soluções: Álcool (70\% - densidade de aprox. 0,8 g/mL), água destilada (densidade aprox. de $1 \mathrm{~g} / \mathrm{mL}$ ) e água saturada com $\mathrm{NaCl}$ (densidade de aprox. $1,2 \mathrm{~g} / \mathrm{mL}$ ). A discussão se deu a partir do comportamento de flutuação ou imersão dos 
materiais nestas soluções. Assim, com diferentes exemplos de materiais poliméricos, classificou-se os mesmos materiais de acordo com sua densidade, de forma semelhante como é feito em escala industrial.

Ao final, foi apresentado e discutido um vídeo sobre classificação de plásticos utilizados no cotidiano, relacionando-os com riscos à saúde.

\begin{tabular}{l|c} 
Material & Densidade $\left(\mathrm{g} / \mathrm{cm}^{3}\right)$ \\
\hline PP & $0,90-0,91$ \\
\hline PEAD & $0,94-0,96$ \\
\hline PS & $1,04-1,08$ \\
\hline PVC & $1,22-1,30$ \\
\hline
\end{tabular}

O esquema de separação desses materiais é:

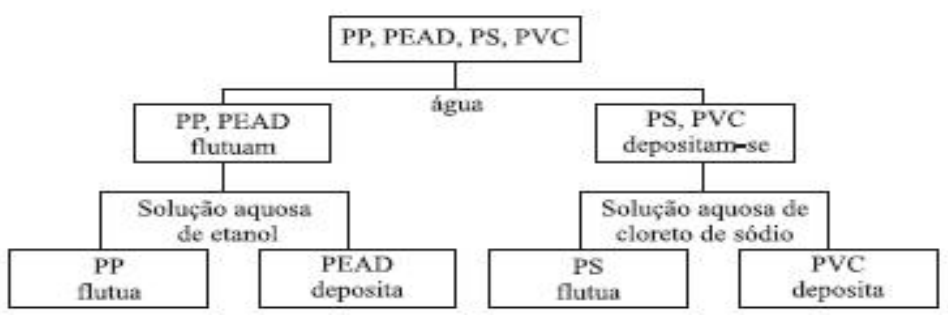

Figura 5. Sistematização para separação de materiais poliméricos, similar ao proposto na atividade experimental

Fonte. Vestiporvas (2004)

\section{Aula 08}

A última aula da Sequência Didática, que compreende a Polinização, foi idealizada para socialização das informações pesquisadas. Os grupos, através de apresentação oral, socializaram as principais informações da pesquisa realizada ao longo das aulas anteriores. Além disso, a parte escrita dos trabalhos de pesquisa dos estudantes foi organizada pelo licenciando numa espécie de portfólio que foi publicado no site da escola, proporcionando a polinização dos conhecimentos construídos para toda a comunidade escolar e demais interessados. Para devida contextualização dos trabalhos produzidos pela turma, foi apresentado também um texto introdutório justificando a relevância do trabalho de pesquisa, da temática e da abordagem social, científica e econômica da pesquisa.

\section{Ensino para Cidadania e o Projeto de Intervenção "Polímeros Plásticos aplicados à Construção Civil": algumas considerações}

A partir do relato do projeto desenvolvido na EEBIMT, pode-se estabelecer algumas considerações a respeito de sua articulação com as características do Ensino de Química para a formação da Cidadania, conforme sinalizado por Santos e Schnetzler (1996) e apresentado no início deste artigo. A primeira ponderação a ser feita refere-se à forma como todo o projeto foi pensado e desenvolvido a partir da abordagem de uma temática, a qual propiciou contextualização dos conteúdos de Química previstos no 
currículo da escola, de forma articulada com o cotidiano dos alunos. Desta forma, houve o atendimento de uma das condições, enfatizadas pelos educadores entrevistados por Santos e Schnetzler (1996), como sendo essencial para o ensino em questão: o desenvolvimento dos processos de ensino-aprendizagem por meio de um tema químico social.

Com relação aos conteúdos de Química abordados, fez-se presente também a característica de ensino para cidadania relativa ao uso de uma linguagem química simplificada, porém, suficiente e necessária para compreensão da temática proposta. Construir com os alunos conhecimentos químicos sobre polímeros plásticos foi um tópico fundamental para compreensão de aspectos sociais e ambientais relacionados a estes produtos presentes no cotidiano dos alunos, bem como para interpretação das informações que costumam ser abordadas nas mídias sobre o descarte incorreto e consumo deliberado destes produtos.

Além disso, entende-se que essa abordagem não foi feita de forma aleatória ou apenas em tom de curiosidade. Na maioria das aulas, buscou-se que a mesma fosse feita através da fundamentação em torno dos conceitos químicos e de discussões de aspectos socioambientais relevantes, que exigiam dos alunos posicionamento crítico.

Contudo, tendo em vista uma reflexão crítica do desenvolvimento do projeto, se faz importante destacar que em determinados momentos a articulação entre tema e conteúdos não foi alcançada ou se deu de forma mais frágil. Exemplo disso é o que ocorreu nas aulas 04 e 05 . Tanto do ponto de vista curricular quanto metodológico, tais aulas envolveram uma perspectiva mais tradicional de ensino, evidenciando a importância da continuidade e o aprimoramento de estudos voltados à implementação de propostas de Ensino de Química para Cidadania.

Nas demais aulas, buscou-se a participação ativa dos alunos, através de debates e discussões sobre temáticas de uso de matéria-prima, produção e reciclagem de materiais plásticos, visando desenvolvimento crítico e tomada de decisão pelos alunos, envolvendo conceitos químicos e aspectos sociais da vida do aluno, devido plásticos ser um grande problema atual global, onde a compreensão de conceitos básicos são necessários para atividade em sociedade pelos alunos. Uma dificuldade com relação a este aspecto foi devido aos alunos estarem habituados com abordagens mais tradicionais de Ensino, sendo uma barreira encontrada pelo docente com relação ao desenvolvimento das atividade de diálogo e debate. Sobre isso, conforme apontam Pukall, Souza e Silva e Silva (2017), não se pode pensar em mudanças no sistema de ensino sem mudar os sujeitos que fazem parte da instituição escolar, sendo necessária a reflexão e tomada de consciência de cada um acerca de seus papéis nos processos de ensino-aprendizagem.

A articulação entre os tipos de materiais poliméricos e seu uso na construção civil almejou que os participantes desenvolvessem conhecimentos e opinião com relação ao uso e consequência da aplicação destes materiais em construções civis, perante julgamento de benefícios e prejuízos da utilização dos mesmos.

Outro aspecto presente foi a utilização da experimentação, buscando a classificação e distinção de materiais plásticos por meio de um experimento bem simples, porém, semelhante aos processos de separação utilizados em larga escala industrial. A atividade foi realizada de modo a propiciar a visualização de características dos materiais poliméricos, objetivando a observação das diferenças de densidade dos materiais poliméricos, instigando o papel investigativo da experimentação. Essa mesma atividade envolveu articulação entre os níveis macroscópico e microscópico de materiais 
poliméricos, de forma simplificada, utilizando analogias para fuga de complexidade de conceitos científicos.

\section{Considerações finais}

O projeto de intervenção "Polímeros Plásticos aplicados à Construção Civil" propôs diferentes atividades e metodologias para o Ensino de Química. Através da perspectiva teórica-metodológica de formação para Cidadania, puderam ser vivenciadas diferentes experiências pelo autor do projeto de intervenção. A experiência de construção e desenvolvimento do projeto apresentou algumas mudanças de paradigmas tradicionais de ensino, buscando não apenas construção de conhecimento por parte dos alunos, mas também debate de temáticas socioambientais vivenciadas atualmente, objetivando desenvolvimento de pensamento crítico, utilizando a Química como ferramenta para interpretação de informações, observação de fenômenos e construção de conhecimentos.

Uma das dificuldades da construção e execução de projetos contextualizados é a quebra de paradigmas tradicionais, que vêem o aluno de forma passiva com relação à construção de conhecimentos, embasados em práticas conteudistas e descontextualizadas de situações sociais do cotidiano dos alunos. Assim, aspectos desse perfil formativo estão internalizados nas práticas de Ensino, e também nos alunos, sendo outra dificuldade a ser encarada pelos professores que buscam novas práticas de Ensino, na perspectiva da formação para a vida em sociedade e objetivando a participação ativa dos sujeitos para o desenvolvimento da capacidade de tomada de decisão crítica.

Dessa forma, a construção e desenvolvimento do projeto de intervenção "Polímeros Plásticos aplicados à Construção Civil" pode ser compreendida como uma tentativa de ensino voltado para a cidadania. Além de apresentar atividades que buscaram estimular a construção coletiva de conhecimentos através de debates e discussões, visou à formação socioambiental dos alunos considerando o contexto em que estágio foi realizado, estimulando à construção de conhecimentos químicos e tomada de decisão crítica no que se refere ao uso de materiais poliméricos no contexto atual.

\section{Referências}

Aguiar, P. A., Pereira, G.A. e Viella, M. A. L. (2017). O uso da metodologia dos Projetos Criativos Ecoformadores (PCE) no estágio curricular supervisionado de um curso de licenciatura do Instituto Federal de Santa Catarina (IFSC) câmpus São José. Revista Professare, 6(2), 123-140.

Brasil. (2006) Organizações Educacionais Complementares aos Parâmetros Curriculares Nacionais (PCN+). Ciências da Natureza e suas Tecnologias. Brasília: MEC.

Instituto Federal de Santa Catarina - IFSC. (2014). Projeto Pedagógico do curso de Química - Licenciatura. São José: IFSC - Campus São José.

PukallL, J. P. (2017). (Eco)Formação de professores na Educação Básica: uma experiência a partir de Projetos Criativos Ecoformadores. Dissertação (mestrado) - Universidade Regional de Blumenau (FURB). Blumenau: FURB. 
Pukall, J. P., Silva, V. L. e Silva, A. R. (2017). Projetos Criativos Ecoformadores na Educação Básica: uma experiência em formação de professores na perspectiva da criatividade. Blumenau: Nova Letra.

Santos, W. L. P. e Schnetzler, R. P. (2010). Educação em Química: Compromisso com a Cidadania. Ijuí: Unijuí.

Santos, W.L.P. e Schnetzler, R.P. (1996). Função social: o que significa o ensino de química para formar o cidadão? Revista Química Nova na Escola, 4, 28-34.

Schnetzler, R. P. (2002). A pesquisa em ensino de química no Brasil: conquistas e perspectivas. Quím. Nova, 25, 14-24. Doi: http://dx.doi.org/10.1590/S010040422002000800004.

Torre, S. e Zwierewicz, M. (2009). Projetos criativos ecoformadores. In: M. Zwierewivz e S. Torre (Coord.) Uma escola para o século XXI: escolas criativas e resiliência na educação (pp. 153-175). Florianópolis: Insular.

Tura, M. L. R. (2003). A observação do Cotidiano Escolar. In: N. Zago, M. P. Carvalho e R. A. T. Vilela (Org.). Itinerários de Pesquisa: Perspectivas qualitativas em Sociologia da Educação (pp. 183-205). Rio de Janeiro: DP\&A.

Data da recepção: 26/07/2019

Data da revisão: $19 / 10 / 2019$

Data do aceite: $23 / 10 / 2019$ 